\title{
Porous $\mathrm{MnNi}_{2} \mathrm{O}_{4}$ Nanorods as an Efficient Bifunctional Catalyst for Rechargeable $\mathrm{Li}-\mathrm{O}_{2}$ battery
}

\author{
Jun $\mathrm{Li}^{1,2 \dagger}$, Yuan $\mathrm{Li}^{3 \dagger}$, Kun $\mathrm{Guo}^{4}$, Liangliang Zou ${ }^{1, *}$, Qinghong Huang ${ }^{1}$, Zhiqing Zou ${ }^{1}$ and Hui Yang ${ }^{1, *}$ \\ ${ }^{1}$ Shanghai Advanced Research Institute, Chinese Academy of Sciences (CAS), Shanghai, 201210, \\ China \\ ${ }^{2}$ University of the CAS, Beijing 100039, China \\ ${ }^{3}$ Technology Center, China Tobacco Hebei Industrial Company, Ltd., Shijiazhuang 050051, China \\ ${ }^{4}$ Department of Petroleum Engineering, University of Stavanger, 4036 Stavanger, Norway \\ $\dagger$ These authors contribute equally to this work \\ *E-mail: yangh@sari.ac.cn, zoull@ sari.ac.cn
}

doi: $10.20964 / 110403227$

Received: 17 December 2015 / Accepted: 19 January 2016 / Published: 1 March 2016

\begin{abstract}
Spinel-type porous $\mathrm{MnNi}_{2} \mathrm{O}_{4}$ nanorods are prepared using a facile electrospinning and subsequent calcination approach. $\mathrm{A} \mathrm{MnNi}_{2} \mathrm{O}_{4}$ nanoparticle material is also synthesized via the sol-gel method to explore the effect of surface area, pore diameter and pore volume on catalytic activity. The crystal phase and morphology of the samples are confirmed by X-ray diffractometry and transmission electron microscopy. Linear sweep voltammetry analysis shows that the $\mathrm{MnNi}_{2} \mathrm{O}_{4}$ nanorods electrode exhibits better activities in oxygen reduction and evolution reactions than the prepared $\mathrm{MnNi}_{2} \mathrm{O}_{4}$ nanoparticles or Ketjenblack electrodes. The sequenced activities of these three materials are further supported by a reduction in both the discharge and recharge overpotentials during battery tests. Furthermore, batteries with the $\mathrm{MnNi}_{2} \mathrm{O}_{4}$ nanorods present improved rate capability and cyclability compared with the $\mathrm{MnNi}_{2} \mathrm{O}_{4}$ nanoparticles and Ketjenblack. This enhanced performance is explained by the large surface area, mean pore diameter, and pore volume of the $\mathrm{MnNi}_{2} \mathrm{O}_{4}$ nanorods. These results highlight the importance of porous $\mathrm{MnNi}_{2} \mathrm{O}_{4}$ nanorods as a prospective bifunctional catalyst and a potential method of electrospinning to scale up the preparation of catalysts for rechargeable $\mathrm{Li}-\mathrm{O}_{2}$ batteries.
\end{abstract}

Keywords: Lithium-air batteries, $\mathrm{Bi}$-functional catalyst, $\mathrm{MnNi}_{2} \mathrm{O}_{4}$, Porous nanorods

\section{FULL TEXT}

(C) 2016 The Authors. Published by ESG (www.electrochemsci.org). This article is an open access article distributed under the terms and conditions of the Creative Commons Attribution license (http://creativecommons.org/licenses/by/4.0/). 